\title{
Proteolytic release and partial characterization of human sperm-surface glycopeptides
}

H. Tortorella ${ }^{1}$, R.A. Konrath ${ }^{1}$, M.N. Mazzini² and A. Brandelli ${ }^{1}$

\author{
Correspondence \\ A. Brandelli \\ ICTA, UFRGS \\ Av. Bento Gonçalves, 9500 \\ 91501-970 Porto Alegre, RS \\ Brasil \\ E-mail: abrand@vortex.ufrgs.br \\ Research supported by PROPLAN \\ (UFRGS, Brasil), FAPERGS, \\ UNESCO-Cono Sur, SECYT \\ (Universidad de Buenos Aires, \\ Argentina), and $\mathrm{CNPq}$.
}

Received November 14, 1996

Accepted January 20, 1997

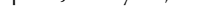

\author{
${ }^{1}$ Laboratório de Fertilidade e Esterilidade Humana, Departamento de Bioquímica, \\ Instituto de Biociências, Universidade Federal do Rio Grande do Sul, \\ 90050-170 Porto Alegre, RS, Brasil \\ 2Departamento de Quimica Orgânica, Facultad de Ciências Exactas y Naturales, \\ Universidad de Buenos Aires, 1428 Buenos Aires, Argentina
}

\begin{abstract}
Sperm-surface glycopeptides were obtained from intact sperm membranes after proteolytic release by different enzymatic treatments such as autoproteolysis, trypsin, papain and pronase. Glycopeptides were isolated, their properties and composition were examined, and their monosaccharide and amino acid constituents were characterized. The monosaccharides identified were fucose, mannose, galactose, $N$-acetylglucosamine, and $\mathrm{N}$-acetylgalactosamine, which form part of more than one type of oligosaccharide units. Autoproteolytic treatment mainly provided $O$-glycosidic type oligosaccharides, while a mixture of $O$ - and $\mathrm{N}$-glycosidic oligosaccharides was obtained in variable proportions when treated with trypsin, papain or pronase. The highest degree of peptide cleavage was obtained with pronase. Despite the higher yields reached with trypsin, these glycopeptides contain the lowest percentage of oligosaccharide chains. Proteolytic treatment provides a simple, rapid procedure for the isolation of glycopeptides from the sperm surface.
\end{abstract}

Key words

- Carbohydrate

- Glycoconjugate

- Proteolysis

- Human sperm

- Peptide

\section{Introduction}

Oligosaccharides are involved in the immunology of sperm and reproduction (1-7) and play a significant role in the spermoocyte interaction (8). Oligosaccharides constitute a singular source of biological relevant compounds for the knowledge of structural features of sperm cell membrane or any cell membrane. Despite their involvement in reproduction and immunological infertility (1), few studies have been carried out regarding the chemical structure of the carbohydrate constituents of the human sperm mem- brane glycoproteins and their nature and composition still remain unclear. Most of the efforts have been directed towards the identification of sperm antigens by immunochemical analysis of sperm cell membrane glycoproteins (2-5).

Human sperm membrane from normal donors was examined and its macromolecular components were isolated and partially characterized (6). Autoproteolysis of normal human sperm produces peptides with oligosaccharide chains of the $N$-glycoside-linked type that are released from the surface-exposed parts of the glycoproteins. Cytochemi- 
cal characterization and localization of the $N$-glycoside-linked oligosaccharide receptors indicated that some are cryptic ones that become exposed by the action of proteolytic enzymes, and most receptors on the acrosome are eliminated when digestion is carried out in the presence of seminal plasma (6).

In the present investigation, the glycopeptides from human sperm membrane glycoproteins were studied in order to determine some of their chemical characteristics. These glycopeptides contain the carbohydrate moiety of the glycoproteins, and were obtained by the action of proteolytic hydrolases (autoproteolysis and extrinsic enzymes) on the sperm membrane.

\section{Material and Methods}

\section{Reagents}

Pronase (Streptomyces griseus protease, type XXV), papain (from papaya latex), and trypsin (from bovine pancreas, type III) were obtained from Sigma Chemical Co. All chemicals used were of analytical grade from Merck.

\section{Isolation of sperm}

Sperm were obtained from healthy donors and isolated according to the method of Saji et al. (9). Semen was diluted with five volumes of phosphate buffered saline (PBS) and centrifuged at $840 \mathrm{~g}$ for $10 \mathrm{~min}$. The supernatant was discarded and the cells were washed three times with the same buffer.

\section{Proteolytic release of glycopeptides from sperm membranes}

Washed sperm were suspended in PBS (for autoproteolysis), trypsin $(0.8 \mathrm{mg} / \mathrm{ml}$ PBS), activated papain (10) $(0.8 \mathrm{mg} / \mathrm{ml} \mathrm{PBS})$, or pronase $(160 \mu \mathrm{g} / \mathrm{ml}$ PBS containing $4 \mathrm{mM}$ $\mathrm{CaCl}_{2}$ ), and then incubated at $37^{\circ} \mathrm{C}$. Release of glycopeptides was followed by periodic removal of aliquots $(100 \mu \mathrm{l})$, centrifugation and assays for changes in the protein content and liberation of free amino acids and low molecular weight peptides. After incubation, the total supernatant containing the glycopeptide mixture was centrifuged at $2,840 \mathrm{~g}$ for $10 \mathrm{~min}$ at $4^{\circ} \mathrm{C}$, concentrated and freeze-dried.

\section{Analytical methods}

Protein analysis was carried out by the method of Lowry et al. (11). Total carbohydrate was determined by the phenol-sulfuric acid method (12), and low molecular weight peptides by the ninhydrin method (13).

\section{Gas-liquid chromatography (GLC)}

Monosaccharide analysis was carried out as described by Reinhold (14), employing the trimethylsilyl derivatives of the corresponding methyl glycosides. A HewlettPackard 5840 gas chromatograph was used. A W-HP column was eluted with nitrogen at $29 \mathrm{ml} / \mathrm{min}$. Monosaccharides were obtained by trifluoroacetic acid treatment for $2 \mathrm{~h}$ at $121^{\circ} \mathrm{C}$, followed by methanolysis for $16 \mathrm{~h}$ at $65^{\circ} \mathrm{C}$. The ratio $O$ - versus $N$-glycosidic linkages was estimated presuming that all GalNAc is present in $O$-glycosidic type chains, and is reported as mol GalNAc relative to $\mathrm{Man}=3(15,16)$, i.e., $\left(O-/ N_{-}\right)=$ (GalNAc)/(Man/3).

\section{Amino acid analysis}

Amino acid analysis was performed as described elsewhere (17), using a Technicon Sequential Multi-Sample Amino Acids Analyzer TM $S 2$ and the amino acids obtained by peptide hydrolysis with $6 \mathrm{M} \mathrm{HCl}$ at $105^{\circ} \mathrm{C}$ for $24 \mathrm{~h}$. Amino acids were purified with Amberlite IR-120 before analysis.

\section{Trypan blue incubation}

Aliquots of sperm suspensions were diluted with an equal volume of $2 \%$ Trypan 
blue in PBS, incubated at $37^{\circ} \mathrm{C}$ for $15 \mathrm{~min}$ and centrifuged for $5 \mathrm{~min}$ at $900 \mathrm{~g}$. The sperm pellet was washed in PBS until the supernatant became clear or pale blue (generally 2 washes), and then fixed for $30 \mathrm{~min}$ in formaldehyde. Formaldehyde was removed by centrifuging the sperm and washing the pellet in deionized water. Fixed sperm were placed on slides and air-dried. The slides were examined under a bright-field microscope at 1000X magnification, and at least 100 cells/sample were evaluated for each of 2 replicates.

\section{Gel filtration chromatography}

Fractions from proteolytic treatments were dissolved in water and loaded on a column $(40 \times 2 \mathrm{~cm})$ of Bio-Gel P-6DG, exclusion limit $6 \mathrm{kDa}$ (Bio-Rad Laboratories), equilibrated with water. Elution was performed with water at room temperature and 5-ml fractions were collected and monitored for carbohydrate and protein. The presence of salts was detected using the silver nitrate reagent.

\section{Results}

Sperm from normozoospermic donors were submitted to autoproteolysis and treatment with pronase, papain and trypsin to obtain glycopeptides from surface glycoproteins. Proteolysis was monitored over time and aliquots were analyzed for free amino acids and low molecular weight peptides, proteins, and carbohydrates.

The production of free amino acids and low molecular weight peptides varied slightly with the type of enzyme and/or sample. The protein/peptide release showed a regular pattern with an increased rate during the first 4 $\mathrm{h}$ followed by a concomitant decrease in the production of amino acids and low molecular weight peptides (see Figure 1, for trypsintreated samples). Autoproteolysis produced larger amounts in some samples and contin- ued without reaching a constant value as observed in the other treatments. Nevertheless, all samples showed the expected behavior with the enzymatic treatments, i.e., a decrease in protein content and an increase in amino acid amount against time.

The release of carbohydrate chains at different times is shown in Figure 2. Papain treatment caused the release of larger amounts of carbohydrates than trypsin or autoproteolysis at $4 \mathrm{~h}$, although similar values were reached by later incubation with trypsin. Treatment of sperm with pronase produced a release of $115 \mu \mathrm{g}$ carbohydrates per $\mathrm{mg}$ total sperm protein after $1 \mathrm{~h}$.
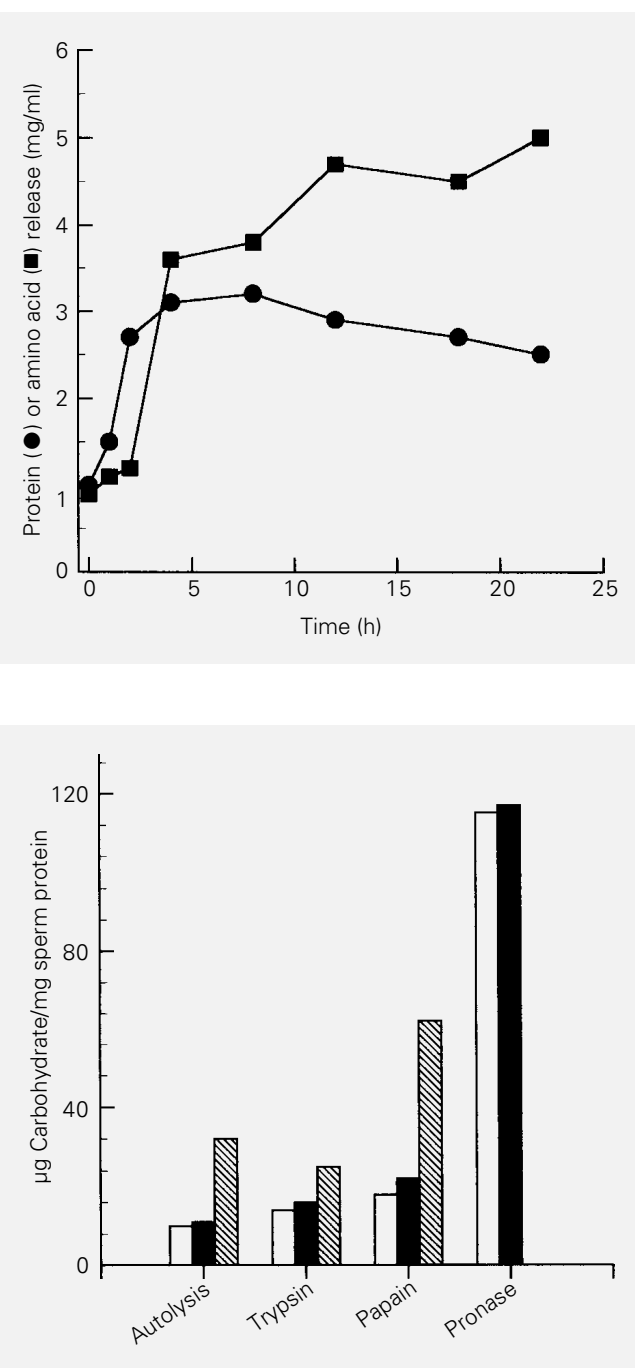

Figure 1 - Time course of protein $(\bullet)$ and amino acid (घ) release by proteolytic treatments. The figure presents data for trypsin-treated normozoospermic samples as a typical pattern of peptide release. Sperm $\left(90 \times 10^{6}\right)$ were incubated at $37^{\circ} \mathrm{C}$ in PBS containing $0.8 \mathrm{mg} / \mathrm{ml}$ trypsin for different times. Assays for amino acids/ low molecular weight peptides, and proteins were carried out by the ninhydrin and Lowry methods, as described in Material and Methods.

Figure 2 - Release of the spermsurface glycopeptides by proteolytic treatments. Sperm were suspended in PBS (for autoproteolysis), trypsin (0.8 $\mathrm{mg} / \mathrm{ml}$ PBS), activated papain $(0.8 \mathrm{mg} / \mathrm{ml} \mathrm{PBS})$, or pronase $(160 \mu \mathrm{g} / \mathrm{ml}$ PBS containing 4 $\mathrm{mM} \mathrm{CaCl} 2$ ), and then incubated at $37{ }^{\circ} \mathrm{C}$. Aliquots were removed at $1 \mathrm{~h}(\mathbf{\square}), 2 \mathrm{~h}(\mathbf{\square})$, and $4 \mathrm{~h}(\mathbf{\nabla})$, and then assayed for carbohydrates and proteins, as described in Material and Methods. Data are reported as $\mu \mathrm{g}$ carbohydrate released per mg sperm protein as sperm substrate at $\mathrm{t}=0$. 
After prolonged incubation the cells became immotile, but were apparently intact by the criteria of light microscopy. To provide more evidence about the status of sperm, cell damage was evaluated using the vital stain Trypan blue. An increase in cell death was observed after $4 \mathrm{~h}$ for autoproteolysis

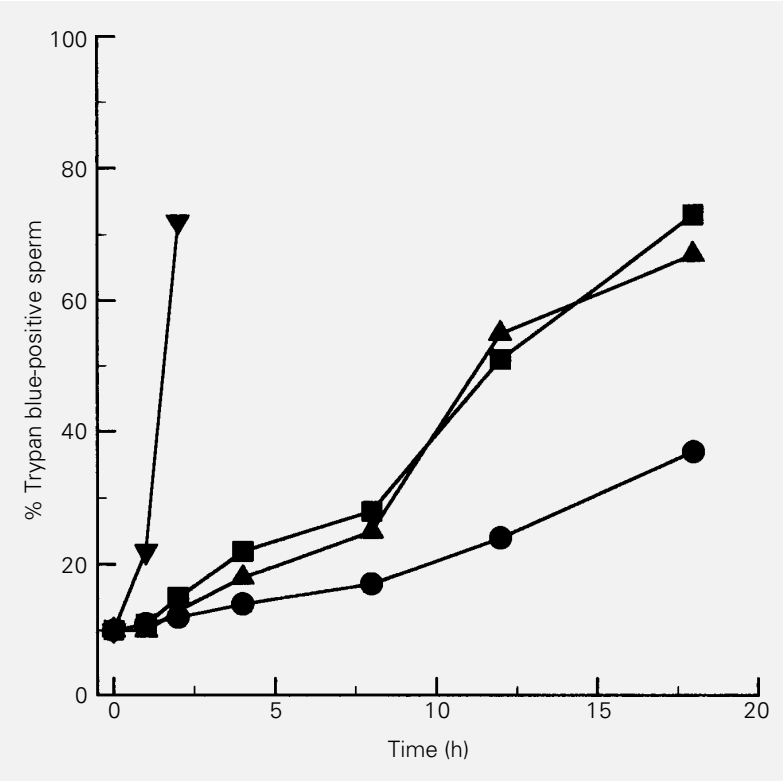

Figure 3 - Sperm viability after proteolytic treatments. Sperm were incubated as described in the legend to Figure 2 and then submitted

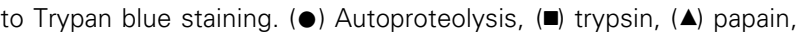
( $\mathbf{)}$ pronase.

Table 1 - Release of glycopeptides from the surface of normal human sperm.

Sperm were incubated as described in the legend to Figure 2 and the glycopeptides released at $4 \mathrm{~h}$ (trypsin, papain or autoly$\mathrm{sis}$ ) or at $1 \mathrm{~h}$ (pronase) were analyzed. Yield is reported as $\mathrm{mg}$ dry weight/20 normospermic samples containing 80-140 x 106 cells. ${ }^{a}$ Non-dialyzable material after autoproteolysis: $21 \%$ amino acid/low molecular weight peptide content; small quantities of NeuNAc were also detected by the Warren assay (37). Glycopeptides of mass higher than $6 \mathrm{kDa}$ were not detected by size exclusion chromatography on Bio Gel P-6DG.

\begin{tabular}{lrcc}
\hline Treatment & Yield & Carbohydrate (\%) & Protein (\%) \\
\hline Autoproteolysis & 3.5 & 27.2 & 67.0 \\
Non-dialyzable $^{\mathrm{a}}$ & 3.2 & $>28.0$ & 51.0 \\
Trypsin & 10.1 & 11.8 & 63.7 \\
Papain & 7.7 & 18.5 & 78.9 \\
Pronase & 5.9 & 25.0 & 71.4
\end{tabular}

which caused lower levels of cell injury than the treatments with trypsin and papain (Figure 3). After 1-h incubation with pronase, the percentage of Trypan blue-positive sperm increased by $18 \%$. Digestion of sperm for a prolonged time with no disintegration of cells was previously observed by Mazzini et al. (6).

Samples obtained from the above treatments were isolated and studied. The glycopeptide mixtures released at $4 \mathrm{~h}$ (treatments with trypsin, papain or autolysis) or at $1 \mathrm{~h}$ (pronase treatment) were analyzed by size exclusion chromatography. A similar profile of molecular weight distribution was observed within two main fractions: the glycopeptide-containing fraction eluted with the void volume (exclusion limit $6 \mathrm{kDa}$ ) and a polydisperse fraction containing the free amino acids and low molecular weight peptides (data not shown). Some yields of the isolated sperm glycopeptide fractions are shown in Table 1 . The carbohydrate content of the produced glycopeptides was monitored and calculated as shown in Table 1.

The carbohydrate composition of the oligosaccharide chains was analyzed. The monosaccharides found were fucose, mannose, galactose, $\mathrm{N}$-acetylglucosamine and $\mathrm{N}$-acetylgalactosamine (Table 2). Galactose was always the main constituent, with variable proportions of the other monosaccharides. Glucose was identified mainly in autolyzed and trypsin-treated samples.

$O$ - versus $N$-linked oligosaccharide ratios were estimated as described in Material and Methods. As shown in Table 2, autoproteolysis produced a molar ratio of $O$-glycosidic to $N$-glycosidic oligosaccharide chains of 10:1; trypsin and papain released elevated amounts of $N$-type oligosaccharides. When sperm were treated with pronase higher amounts of $N$-glycosidic chains were obtained (molar ratio $O$ - $/ N$ - was 1:2).

Amino acid analysis was carried out on representative samples only. Aspartate, threonine, serine and glutamate were the main 
constituents of the peptide moiety together with variable amounts of alanine, glycine, leucine, and lysine (Table 3 ). The percentages of the amino acids involved in the proteolysis breakdown, namely, tyrosine, lysine and arginine, were variable and usually low. Methionine was not detected.

\section{Discussion}

The sperm-surface glycopeptides from normospermic donors were examined. Sperm antigen preparations are difficult to deal with because of the somewhat rigid sperm cell membrane that resists the usual solubilization methods. For the isolation of glycopeptides we used autoproteolysis, a technique which has been previously demonstrated to be useful (6). Other types of proteolytic enzymatic degradation were also investigated, such as trypsin and papain which have a more defined action, and pronase which has a wide specificity of action, cleaving glycosylated proteins of the membrane surface (18).

Acrosin, the sperm-specific protease involved in several aspects of fertilization $(19,20)$, and trypsin possess similar proteolytic activity and specificity for peptide bonds which involve the basic amino acids lysine and arginine. Pronase is less specific (hydrolyzes arginine bonds and others) and differs from trypsin and other proteases since there are no known pronase inhibitors in the human sperm. Papain is commonly used for the release of ectoenzymes from membranes without incurring any loss of activity $(21,22)$. Proteolytic enzymes other than acrosin have been extracted from sperm but are not well characterized, and activities of fibrinolytic enzymes (seminin), plasminogen activators, pepsin-like proteinase, aminopeptidase and dipeptidase have been described in seminal plasma (23). Treatments with extrinsic enzymes also involve intrinsic proteases activated by the hydrolytic conditions which characterize the autoproteolytic treatment.

The results of the enzymatic treatment, despite showing a similar pattern for the release of the glycoconjugates, indicate some important differences and also the accessibility or exposure of the carbohydrate chains on the sperm membrane to the action of the

Table 2 - Monosaccharide composition of human sperm-surface glycopeptides released by different proteolytic enzymes.

Sperm were incubated as described in the legend to Figure 2 and the glycopeptides released at $4 \mathrm{~h}$ (trypsin, papain or autolysis) or at $1 \mathrm{~h}$ (pronase) were analyzed. Results are reported as mol\%. The molar ratio of O-glycosidic to $\mathrm{N}$-glycosidic oligosaccharide chains was estimated as described in Material and Methods.

\begin{tabular}{lrrrr}
\hline Monosaccharide & Autolysis & Trypsin & Papain & Pronase \\
\hline Fucose & 21.1 & 11.7 & 17.6 & 15.3 \\
Mannose & 4.9 & 16.9 & 9.3 & 26.2 \\
Galactose & 41.5 & 33.4 & 36.2 & 37.2 \\
Glucose & 8.2 & 8.4 & 7.9 & 0.8 \\
N-Acetylgalactosamine & 16.5 & 17.0 & 15.8 & 4.0 \\
N-Acetylglucosamine & 7.8 & 12.6 & 13.2 & 16.5 \\
O-/N-ratio & $10: 1$ & $3: 1$ & $5: 1$ & $1: 2$ \\
& & & &
\end{tabular}

Table 3 - Amino acid composition of human sperm glycopeptide fractions obtained by proteolytic treatment of normal sperm samples.

Data are reported as mol\% after acid hydrolysis.

\begin{tabular}{lrrrr}
\hline Amino acid & Autolysis & Trypsin & Papain & Pronase \\
\hline Asp & 10.6 & 13.6 & 9.3 & 14.6 \\
Thr & 10.0 & 6.8 & 6.2 & 8.1 \\
Ser & 8.0 & 7.8 & 13.1 & 9.3 \\
Glu & 20.5 & 21.4 & 23.5 & 25.2 \\
Pro & 4.3 & 3.9 & 4.0 & 6.3 \\
Gly & 4.6 & 3.9 & 4.3 & 7.1 \\
Ala & 4.1 & 5.8 & 5.0 & 10.1 \\
Val & 4.6 & 3.9 & 0.0 & 0.0 \\
Met & 0.0 & 0.0 & 0.0 & 0.0 \\
Ile & 3.3 & 9.0 & 4.3 & 0.0 \\
Leu & 12.3 & 7.3 & 14.5 & 7.6 \\
Tyr & 2.8 & 2.0 & 2.7 & 0.0 \\
Phe & 1.7 & 2.4 & 1.7 & 0.0 \\
His & 4.2 & 2.8 & 2.1 & 0.0 \\
Lys & 5.4 & 6.3 & 6.5 & 4.6 \\
Arg & 3.6 & 3.1 & 2.8 & 7.1
\end{tabular}


different enzymes. The differences observed in the monosaccharide composition of the sperm membrane glycopeptides released after different enzymatic treatments indicate that important variations in the nature of the glycopeptides occur according to the mode of action of the enzyme(s).

The monosaccharides galactose, fucose, mannose, $\mathrm{N}$-acetylglucosamine and $\mathrm{N}$ acetylgalactosamine, that are present in the sugar moiety of human sperm as indicated by lectin studies $(24,25)$, were identified in the present study. Glucose found in considerable relative proportions in some cases is not a usual monosaccharide in glycoproteins (26), and therefore may indicate release of a glycolipid component from the membrane in the case of prolonged treatment (autolysis, trypsin and papain), but not in the case of degradation with pronase which is fast and effective (30-60 min) (27). The carbohydrate composition of these glycopeptides is unlike that of either the $\mathrm{N}$-glycosyl or the $O$ glycosyl type, since it contains GalNAc as well as Fuc and Glc, in addition to Man, Gal and GlcNAc residues. However, in the peptide moiety, a significant content of Asp and/ or $\mathrm{Thr} / \mathrm{Ser}$ suggests a predominant proportion of both $N$ - and $O$-glycosylated chains in the original glycoprotein. Under mild conditions, trypsin caused the removal of glycoprotein from the surface of Macaca radiata sperm (28) and from human semen (29), albeit of higher molecular weight, results similar to those obtained in the present investigation.

The Asp (Asp + Asn) and Ser + Thr contents of the autolysis products were 10.6 and $18.0 \mathrm{~mol} \%$, respectively. Hence, the $O-/$ $\mathrm{N}$ - ratio can only be 10:1 if the $\mathrm{N}$-glycosylated Asn is $1.8 \mathrm{~mol} \%$, or $17 \%$ of Asp content of the amino acid analysis. Extending the same rationale to the other treatments, the $N$ - glycosylated Asn is 36\% for trypsin and $41.5 \%$ for papain. In the case of pronase treatment, the $O-/ N$ - ratio was estimated as $1: 2$, indicating a relative higher number of $N$-linked carbohydrates.

The specific shape of complex oligosaccharide-protein structures located on the extracellular side of membrane-bound peptides is thought to be responsible for their function as carriers of significant biological information and cellular recognition (30-32). The importance of these oligosaccharides in reproductive physiology has been demonstrated by several observations. The human sperm cell membrane antigen gp12, which is highly specific for sperm and seminal plasma, has been isolated from a plasma membrane fraction (9). The antigenic determinant of this molecule, recognized by the corresponding antibody, should be located in the sugar portion of the glycoprotein (33). On the other hand, antisperm monoclonal antibodies, reacting to glycosylated epitopes, presented very strong properties of sperm agglutination and/or immobilization (24). Finally, gamete interaction is mediated by protein-carbohydrate recognition (34) and the clustering of sperm receptors to the zona pellucida oligosaccharides has been proposed as a mechanism of acrosomal exocytosis induction $(35,36)$. In conclusion, the present study provides relevant information about the chemical properties of human sperm-surface glycopeptides.

\section{Acknowledgments}

We thank A. Heuck for valuable technical assistance, UMYMFOR (FCEyNCONICET, Argentina) for GLC analyses, and Dr. Milvo A. Pozzer (FUEF), and Laboratório de Análises Clínicas da Santa Casa de Misericórdia for semen samples. 


\section{References}

1. Alexander NJ \& Anderson DJ (1987). Immunology of semen. Fertility and Sterility, 47: 192-205.

2. Czuppon AB, Mettler L, Schauer R \& Pawassarat $V$ (1981). Purification of a human sperm antigen. Hoppe-Seyler's Zeitschrift für Physiologische Chemie, 362: 963-968.

3. Olson GE \& Gould KG (1981). Characterization of sperm surface and seminal plasma glycoproteins of the chimpanzee. Journal of Reproduction and Fertility, 62: 185-192.

4. Poulsen $F$ (1983). The nature of an isoantigen of the human sperm membrane. Journal of Reproductive Immunology, 5: 49-54.

5. Lee CG, Lum V, Wong E, Menge AC \& Huang $Y$ (1983). Identification of human sperm antigens to antisperm antibodies. American Journal of Reproductive Immunology, 3: 183-187.

6. Mazzini MN, Ceraci $P$, deCerezo JMS \& Cerezo AS (1986). Carbohydrates of the surface of the normal human spermatozoon. American Journal of Reproductive Immunology and Microbiology, 11: 107111.

7. Tsuji $Y$, Clausen $H$, Nudelman E, Kaizo $T$, Hakomori SI \& Isojima S (1988). Human sperm carbohydrate antigens defined by an antisperm human monoclonal antibody derived from an infertile woman bearing antisperm antibodies in her serum. Journal of Experimental Medicine, 168: 343-356.

8. Miller DJ \& Ax RL (1990). Carbohydrates and fertilization in animals. Molecular Reproduction and Development, 26: 184-198.

9. Saji F, Minagawa Y, Negoro T, Nakamuro K \& Tanizawa $O$ (1985). A human sperm coating antigen isolated from sperm cell membrane. American Journal of Reproductive Immunology and Microbiology, 8: 132-136.

10. Butler PE (1990). Solubilization of membrane proteins by proteolysis. In: Beynon PJ \& Bond JS (Editors), Proteolytic Enzymes. IRL Press, London, 193-200.

11. Lowry $\mathrm{OH}$, Rosebrough NJ, Farr AL \& Randall RJ (1951). Protein measurement with the Folin phenol reagent. Journal of Biological Chemistry, 193: 267-275.

12. Dubois M, Giles KA, Hamilton KA, Rebers PA \& Smith F (1956). Colorimetric method for determination of sugars and related substances. Analytical Chemistry, 28: 350-356.

13. Moore S \& Stein WH (1957). A modified ninhydrin reagent for the photometric determination of amino acids and related compounds. Journal of Biological Chemistry, 211: 907-913.
14. Reinhold VN (1972). Gas liquid chromatographic analysis of constituent carbohydrates in glycoproteins. Methods in Enzymology, 25: 244-249.

15. Montreuil J (1984). Spatial conformation of glycans and glycoproteins. Biology of the Cell, 51: 115-132.

16. Montreuil J, Bouquelet $S$, Debray $H$, Fournet B, Spik G \& Strecker G (1986). Glycoproteins. In: Chaplin MF \& Kennedy JF (Editors), Carbohydrate Analysis. IRL Press, Oxford, 143-204.

17. Mazzini MN, Di Giacomo MA \& Cerezo AS (1987). Hydrophobic interaction chromatography of autoproteolysis products of human seminal plasma. Biomedical Chromatography, 2: 152-155.

18. Cook GMW (1976). Techniques for the analysis of membrane carbohydrates. In: Maddy AH (Editor), Biochemical Analysis of Membranes. Chapman \& Hall Ltd., London, 283-351.

19. Töpfer-Petersen $E$, Steinberger $M$, Von Eschenbach CE \& Zucker A (1990). Zona pellucida-binding of boar sperm acrosin is associated with the $\mathrm{N}$-terminal peptide of the acrosin ß-chain (heavy chain). FEBS Letters, 265: 51-54.

20. Eberspaecher U, Gerwien J, Habenicht UF, Schleuning WD \& Donner P (1991). Activation and subsequent degradation of proacrosin is mediated by zona pellucida glycoproteins, negatively charged polysaccharides, and DNA. Molecular Reproduction and Development, 30: 164-170.

21. Louvard D, Maroux S, Vannier C \& Desnuelle P (1975). Topological studies on the hydrolases bound to intestinal brush border membrane. Solubilization by papain and Triton X-100. Biochimica et Biophysica Acta, 375: 236-248.

22. Maestracci D (1976). Enzymatic solubilization of the human intestinal brush border enzymes. Biochimica et Biophysica Acta, 433: 469-481.

23. Morton DB (1977). The occurrence and function of proteolytic enzymes in the reproductive tract of mammals. In: Barrett AJ (Editor), Proteinases in Mammalian Cells and Tissues. Elsevier/North Holland, Amsterdam, 445-500.

24. Kurpisz M \& Alexander NJ (1995). Carbohydrate moieties on sperm surface: physiological relevance. Fertility and Sterility, 63: 158-165.

25. Cross NL \& Overstreet JW (1987). Glycoconjugates of the human sperm surface: distribution and alterations that accompany capacitation in vitro. Gamete Research, 16: 23-35.
26. Montreuil J (1980). Primary structure of glycoprotein glycans: basis for the molecular biology of glycoproteins. Advances in Carbohydrate Chemistry and Biochemistry, 37: 157-223.

27. Harrison R, Higginbotham JD \& Newman R (1975). Sialoglycopeptides from bovine milk fat globule membrane. Biochimica et Biophysica Acta, 389: 449-463.

28. Nasir UD, Walker-Nasir E, Jeanloz RW \& Shalev M (1980). Isolation and identification of spermatozoon-surface glycoproteins from Macaca radiata. Carbohydrate Research, 85: C7-C9.

29. Nasir UD, Walker-Nasir E, Ajaz Z \& Malghani MA (1984). Sperm-surface glycoproteins: isolation, purification and partial characterization. In: Vliegerithart JGF, Karuberlinig JP \& Veldirek GA (Editors), Abstracts of the XIIth International Carbohydrate Symposium. Vorik Publishers, Utrecht, The Netherlands, 249.

30. Taylor ME \& Drickamer K (1993). Structural requirements for high affinity binding of complex ligands by the macrophage mannose receptor. Journal of Biological Chemistry, 268: 399-404.

31. Zanetta JP, Kuchler S, Lehmann S, Badache A, Maschke S, Thomas D, Dufourca P \& Vicendon G (1992). Glycoproteins and lectins in cell adhesion and cell recognition processes. Histochemical Journal, 24: 791-804.

32. Weston AS \& Parish CR (1992). Evidence that mannose recognition by splenic sinusoidal cells plays a role in the splenic entry of lymphocytes. European Journal of Immunology, 22: 1975-1981.

33. Saji F, Minagawa Y, Ohashi K, Negoro T \& Tanizawa O (1986). Further characterization of a human sperm coating antigen. American Journal of Reproductive Immunology and Microbiology, 12: 13-16.

34. Macek MB \& Shur BD (1988). Proteincarbohydrate complementarity in mammalian gamete recognition. Gamete Research, 20: 93-109.

35. Leyton L \& Saling PM (1989). Evidence that aggregation of sperm receptors by ZP3 triggers the acrosome reaction. Journal of Cell Biology, 108: 2163-2168.

36. Brandelli A, Miranda PM \& Tezon JG (1994). Participation of glycosylated residues in the human sperm acrosome reaction: possible role of $\mathrm{N}$-acetylhexosaminidase. Biochimica et Biophysica Acta, 1120: 299-304.

37. Warren L (1959). The thiobarbituric acid assay of sialic acids. Journal of Biological Chemistry, 234: 1971-1975. 